[Supporting Information to accompany]

\title{
Anthracene-Induced Turnover Enhancement in the Manganese Porphyrin- Catalyzed Epoxidation of Olefins
}

\section{Melissa L. Merlau, So-Hye Cho, Shih-Sheng Sun, SonBinh T. Nguyen,* and Joseph T. Hupp* \\ Department of Chemistry and Institute for Environmental Catalysis, Northwestern University, 2145 Sheridan Road, Evanston, IL 60208-3113}

Supporting Information Available: TON data for several anthracene additives in (mesotetraphenylporphine) $\mathrm{Mn}^{\mathrm{III}}$ chloride (MnTPP, 1)-catalyzed styrene epoxidation (Eq S1). This material is available free of charge via the Internet at http://pubs.acs.org.

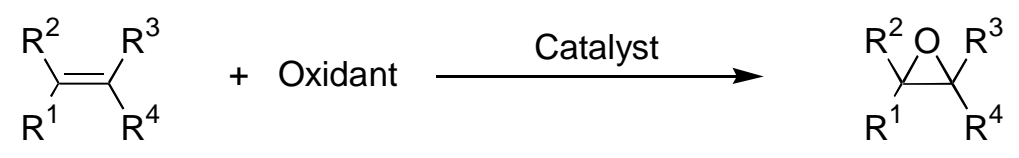

Catalyst $=$
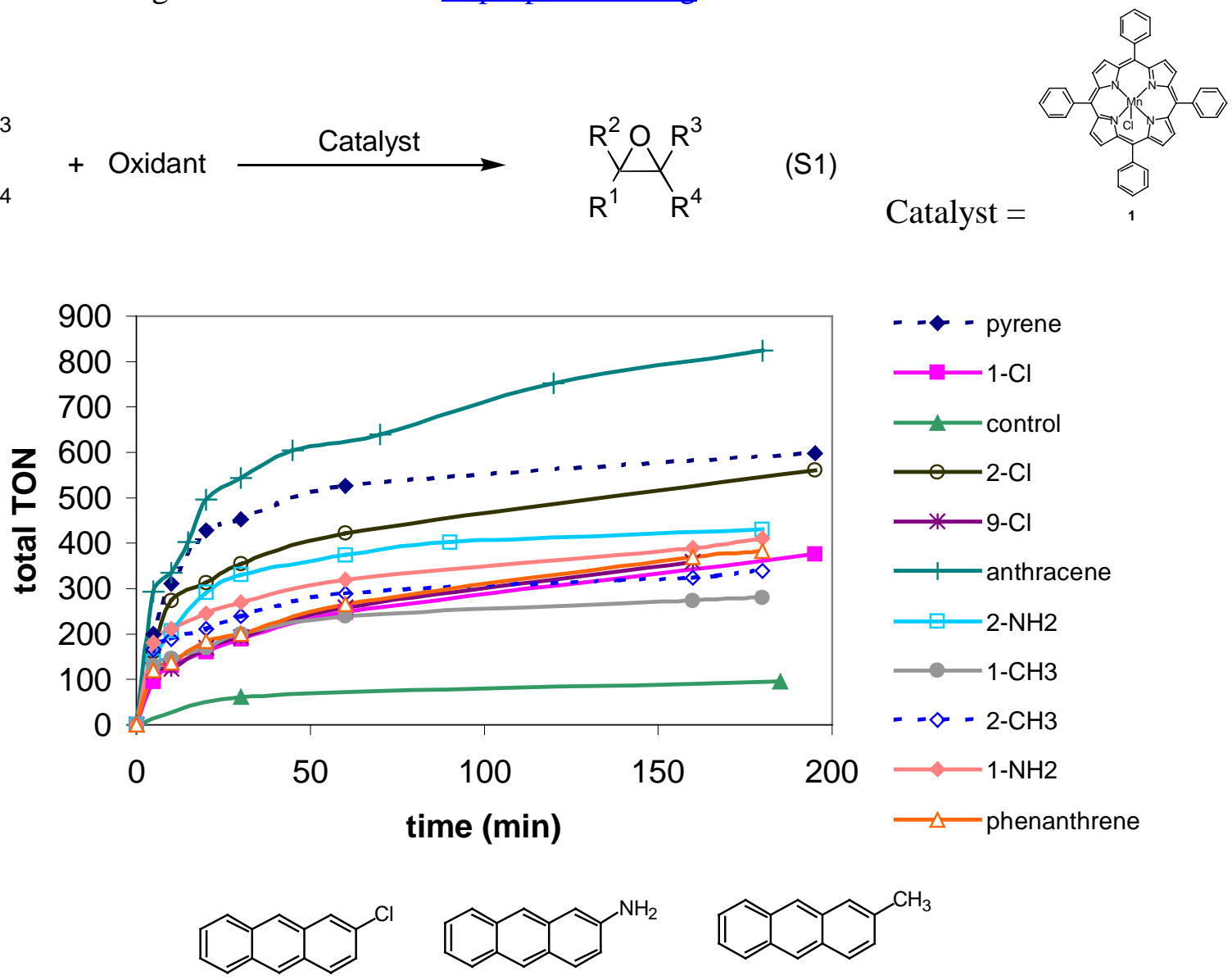<smiles>Clc1cccc2cc3ccccc3cc12</smiles><smiles>Nc1cccc2cc3ccccc3cc12</smiles><smiles>Cc1cccc2cc3ccccc3cc12</smiles><smiles>Clc1c2ccccc2cc2ccccc12</smiles><smiles>c1ccc2c(c1)ccc1ccccc12</smiles><smiles></smiles>

Figure S1. Anthracene derivatives which provide moderate epoxidation TON enhancement in MnTPP-catalyzed styrene epoxidation. 


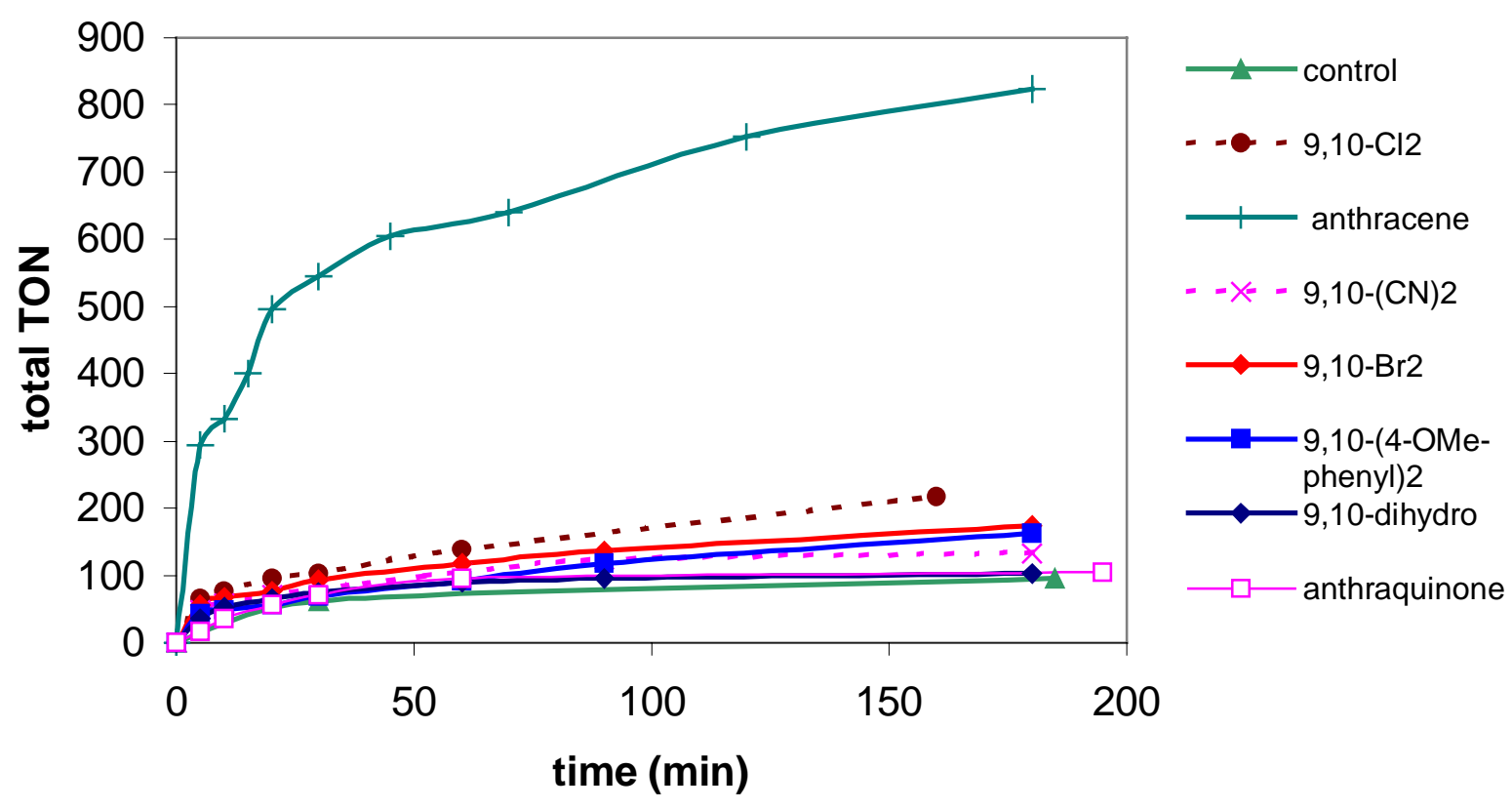<smiles>O=C1C(=O)c2ccccc2C(=O)c2ccccc21</smiles><smiles>N#Cc1c2ccccc2c(C#N)c2ccccc12</smiles><smiles>Brc1c2ccccc2c(Br)c2ccccc12</smiles><smiles>COc1ccc(-c2c(-c3ccccc3)c(-c3ccccc3)c3ccccc3c2-c2ccc(OC)cc2)cc1</smiles><smiles>Clc1c2ccccc2c(Cl)c2ccccc12</smiles>

Figure S2. Anthracene derivatives which provides little epoxidation TON enhancement in MnTPP-catalyzed styrene epoxidation. 